\title{
Fluid pressure drops during stimulation of segmented faults in deep geothermal reservoirs
}

\author{
Guillem Piris ${ }^{1 *} \mathbb{0}$, Albert Griera' ${ }^{1}$ Enrique Gomez-Rivas ${ }^{2,3}$, Ignasi Herms ${ }^{4}$, Mark W. McClure ${ }^{5}$ \\ and Jack H. Norbeck ${ }^{6,7}$
}

*Correspondence:

guillem.piris@uab.cat

${ }^{1}$ Departament de Geologia, Universitat Autònoma de Barcelona, 08193 Bellaterra (Cerdanyola del Vallès), Spain Full list of author information is available at the end of the article

\begin{abstract}
Hydraulic stimulation treatments required to produce deep geothermal reservoirs present the risk of generating induced seismicity. Understanding the processes that operate during the stimulation phase is critical for minimising and preventing the uncertainties associated with the exploitation of these reservoirs. It is especially important to understand how the phenomenon of induced seismicity is related to the pressurisation of networks of discrete fractures. In this study, we use the numerical simulator CFRAC to analyse pressure drops commonly observed during stimulation of deep geothermal wells. We develop a conceptual model of a fractured geothermal reservoir to analyse the conditions required to produce pressure drops and their consequences on the evolution of seismicity, fluid pressure, and fracture permeability throughout the system. For this, we combine two fracture sets, one able to be stimulated by shear-mode fracturing and another one able to be stimulated by opening-mode fracturing. With this combination, the pressure drop can be triggered by a seismic event in the shearstimulated fracture that is hydraulically connected with an opening-mode fracture. Our results indicate that pressure drops are not produced by the new volume created by shear dilatancy, but by the opening of the conjugated tensile fractures. Finally, our results reveal that natural fracture/splay fracture interaction can potentially explain the observed pressure drops at the Rittershoffen geothermal site.
\end{abstract}

Keywords: Enhanced geothermal reservoirs, Pressure drops, Reservoir simulation, Induced seismicity, Fracture networks

\section{Introduction}

Geothermal energy development, either for electricity generation or for direct applications of geothermal heat, can be carried out in a wide range of geological settings. In the case of active tectonic zones with abnormally high geothermal gradients, such as Iceland, Italy, New Zealand or Turkey (Moeck 2014), geothermal energy can be widely exploited at shallow depths. However, geothermal projects usually need to exploit deeper reservoirs in regions where radiogenic igneous rocks are not present or where the tectonic activity is minor. In recent years, the exploration and exploitation of deep geothermal reservoirs have significantly increased worldwide (e.g. Tester et al. 2006; Breede et al. 2013; Király et al. 2015). In this context, geothermal projects focusing on

(c) The Author(s) 2018. This article is distributed under the terms of the Creative Commons Attribution 4.0 International License (http://creativecommons.org/licenses/by/4.0/), which permits unrestricted use, distribution, and reproduction in any medium, provided you give appropriate credit to the original author(s) and the source, provide a link to the Creative Commons license, and indicate if changes were made. 
heat distribution (low and medium enthalpy) have mainly targeted crystalline basement rocks or large and deep sedimentary basins, such as intracratonic basins and foredeep orogenic belts, as well as continental rifts. Projects focusing on power generation in high-temperature, low-permeability settings generally need to be developed as Enhanced Geothermal Systems (EGS), either in fractured crystalline basement rocks, or in sedimentary and volcanic rocks (Zimmermann and Reinicke 2010; Elders et al. 2014).

Although deep, naturally fractured tight reservoirs are normally characterised by the presence of pre-existing fracture networks that provide some permeability. In most cases, the presence of rocks with low permeability prevents the economic feasibility of the project. Exploitation of low-permeability geothermal reservoirs requires the use of hydraulic stimulation techniques to enhance the permeability of the reservoir, increasing fluid flow and heat transfer between injection and extraction wells (Zimmermann and Reinicke 2010; Schill et al. 2017). However, stimulation processes sometimes produce induced seismicity, a hazard that needs to be mitigated to ensure the social acceptance and viability of the project. Normally, when this type of seismicity is low in magnitude, it is rarely felt and is referred to as microseismicity. Nevertheless, in some cases, the events may have high enough magnitude to be noticed at the Earth's surface, putting in risk the viability of the project (e.g. Majer et al. 2007; Häring et al. 2008; Dempsey and Suckale 2015). In such contexts, it is essential that we understand the fundamental processes involved in the hydraulic stimulation phase to reduce seismic risks and characterise the uncertainty of seismic hazard estimates.

Recently, Meyer et al. (2017) reported a strange phenomenon observed during the stimulation of the GRT1 well of the Rittershoffen geothermal power plant (Baujard et al. 2017). This consisted of a series of pressure drops (between $4 \cdot 10^{-3} \mathrm{MPa}$ and $0.16 \mathrm{MPa}$, Fig. 1a) during fluid injection that, according to these authors, seemed to be linked with or followed by a cluster of seismic events (with magnitudes ranging between 0.3 and 1.3; Meyer et al. 2017; Fig. 1b). For systems where permeability is dominated by the preexisting fracture network, key factors that could produce a sudden pressure drop in the system are the rapid generation of permeability or the sudden increase of fluid storage capacity of the fracture network. Although most EGS projects have typically assumed that stimulation occurs principally through shear reactivation of pre-existing fractures, an alternative explanation is the so-called mixed-mechanism stimulation (McClure and
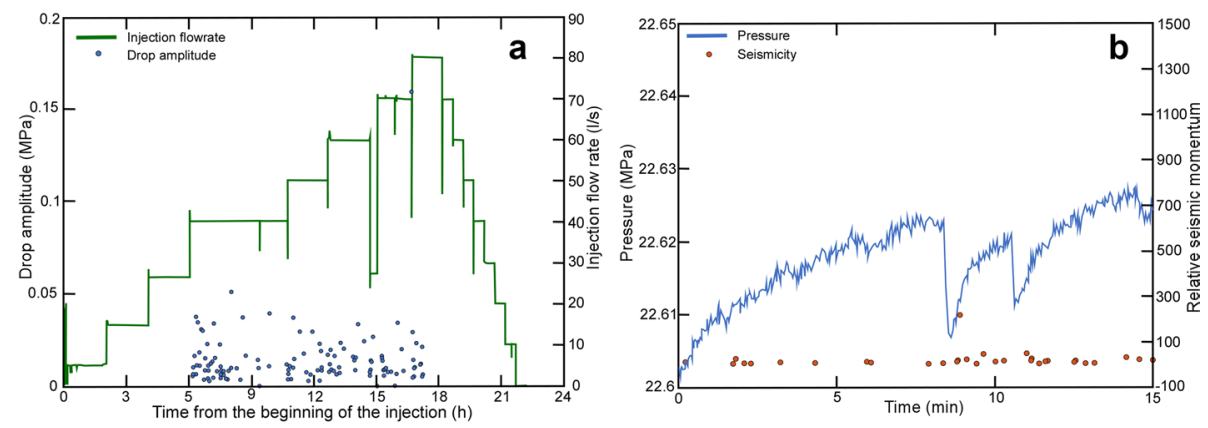

Fig. 1 a Injection flow rate and fluid pressure drop amplitude during fluid stimulation of the GRT1 well at the Rittershoffen geothermal reservoir. $\mathbf{b}$ A detail of the fluid pressure registered at the well showing two examples of pressure drops and the associated seismicity swarm (Figure modified from Meyer et al. (2017)) 
Horne 2014; Norbeck et al. 2018). The mixed-mechanism stimulation involves both (1) shear stimulation by reactivation of previous fractures and (2) the development of new tensile fractures as bridges between pre-existing fractures.

Meyer et al. (2017) proposed three main hypotheses to explain the mechanisms associated with pressure drops and the triggering of induced seismicity. The first hypothesis considers that pressure drops are caused by fracture reactivation and slip with associated microseismicity. In the second hypothesis, they suggest that the phenomenon can be due to pressure equilibration during the connection between the stimulated/hydraulic fractures and the pre-existing ones. When a pressurised hydrofracture (i.e. a new fracture in the reservoir formed during hydraulic stimulation) gets connected with an unpressurised pre-existing fracture, additional fluid storage space is suddenly generated and, as a consequence, a pressure drop can occur. When fluid pressure recovers, stimulation of the newly connected fracture causes instability and slip takes place creating a swarm of seismic events. Finally, the third hypothesis considers that the pressure drop is produced by the propagation and opening of new cracks (i.e. tensile fractures) as wing cracks growing from pre-existing fractures (e.g. Norbeck et al. 2018). During the sliding stimulation phase of a pre-existing fracture, there is a relative displacement between the two fracture walls. This can induce the growth of tensile cracks at their tips, if the tensile strength of the rock is overcome. Such new cracks would also cause a sudden increase of permeability and an associated pressure drop. After running a series of numerical models, Meyer et al. (2017) concluded that the most plausible hypothesis to explain pressure drops is the propagation of new tensile fractures, although their study was not conclusive and suggested that further work was required.

Both hypotheses 2 and 3 proposed by Meyer et al. (2017) share the condition that pressure drops occur in systems that contain or develop at least two sets of fractures at different orientations with respect to the stress field. As previously demonstrated by several studies (e.g. Garagash and Germanovich 2012; Gischig 2015; Piris et al. 2017), rupture propagation and sliding/tensional behaviour on fluid pressurised fractures depend on their relative orientation with respect to the principal stress axes. Fractures with strikes oriented at moderate angles with the maximum compressive stress $\left(\sigma_{1}\right)$ are characterised by reactivation by sliding and/or opening, and are considered seismically active. In contrast, fractures at low angles with $\sigma_{1}$ have the capacity of being stimulated by opening mode and present either an aseismic behaviour or very low-magnitude seismicity (Piris et al. 2017). The new formation or reactivation of the latter set of fractures (i.e., at low angles with $\sigma_{1}$ ) can potentially result in a sudden permeability increase due to their ability to dilate at relatively low fluid pressure. Accordingly, if both fracture sets are connected when a fracture at a moderate angle is reactivated, the slip would induce opening of the aseismic fracture and will, thus, cause a pressure drop. The understanding of this process can potentially be used to identify patterns of the mixed-mechanism stimulation during hydraulic stimulation treatments.

In this study, we present a conceptual model where natural fractures are hydraulically connected by tensile splay fractures. Our overarching aim is to understand the influence of different properties of fracture sets on the system pressurisation and their consequences for seismicity propagation and fault pressurisation in a generic deep geothermal reservoir. We present numerical simulations based on simple fracture 
geometries, avoiding complex fracture networks, to investigate how pressure drops are related to stimulation and induced seismicity. Our results reveal a direct link between pressure drops and seismicity in systems involving two different fracture sets that are hydraulically connected. Seismicity is produced by sliding of a shear-mode fracture that induces a sudden opening of connected hydraulically tensile fractures, thus triggering the pressure drop.

\section{Methods}

The numerical simulations were carried out with the two-dimensional version of the boundary element reservoir simulation code CFRAC (McClure 2012). This software is able to solve the fully coupled hydro-mechanical problem related to the injection of fluid through a fracture network embedded in an impermeable matrix and the associated induced seismicity (McClure and Horne 2011, 2013, 2014). These conditions are those typically found in deep geothermal reservoirs in crystalline basement rocks, where matrix permeability is nearly zero and flow occurs predominantly through fracture networks. The full-field fluid flow evolution and the reactivation of pre-existing fractures (by opening and/or sliding) are solved simultaneously. In these simulations, the fluid is assumed to be single phase (liquid water) and thermal effects are neglected (i.e. simulations are carried out in isothermal conditions). The simulation is initialised under homogeneous, anisotropic stress field conditions and with a homogeneous fluid pressure distribution. CFRAC can simulate both pre-existing fractures and new hydraulically formed fractures. However, the location of potentially forming fractures is defined in advance. The frictional resistance to slip is given by Coulomb's law (Segall 2010):

$$
|\tau-\eta v|=\mu_{\mathrm{f}}\left(\sigma_{\mathrm{n}}-P\right)+S_{0},
$$

where $\tau$ is the shear stress, $\eta$ is the radiation damping coefficient, $v$ is the sliding velocity of the fracture, $\mu_{\mathrm{f}}$ is the friction coefficient, $\sigma_{\mathrm{n}}$ is the normal stress, $P$ is the fluid pressure and $S_{0}$ is the fracture cohesion. The evolution of the friction coefficient was defined using a rate-and-state formulation where this parameter depends on the sliding velocity and the sliding history of the fracture (Scholz 2002; Segall 2010). In terms of aperture change with slip, the approach evaluates separately the changes in fracture conductivity (i.e. hydraulic aperture) and pore volume (i.e. void or mechanical aperture) using two dilatation angles. For a more detailed description of the mathematical formulation used by CFRAC, see McClure (2012) or McClure and Horne (2013).

\section{Model setup}

The initial geometry of the model consisted of a single fracture defined by several linked segments with different orientations with respect to the maximum compressive stress $\left(\sigma_{1}\right)$. Each individual fracture had a length of $60 \mathrm{~m}$ and was discretised into 20-cm-long elements (Fig. 2). The fracture element size was further refined near fracture intersections (with a minimum element size of $0.02 \mathrm{~m}$ ). A constant out-of-plane thickness of $h=100 \mathrm{~m}$ was considered for all models. Segments were orientated at $\alpha=60^{\circ}$ and $\alpha=88^{\circ}$, where $\alpha$ is the angle between $\sigma_{1}$ and the normal of the fracture segment (Fig. 2). These angles were selected because previous studies demonstrated that these orientations result in a highly variable range of seismic behaviour during 


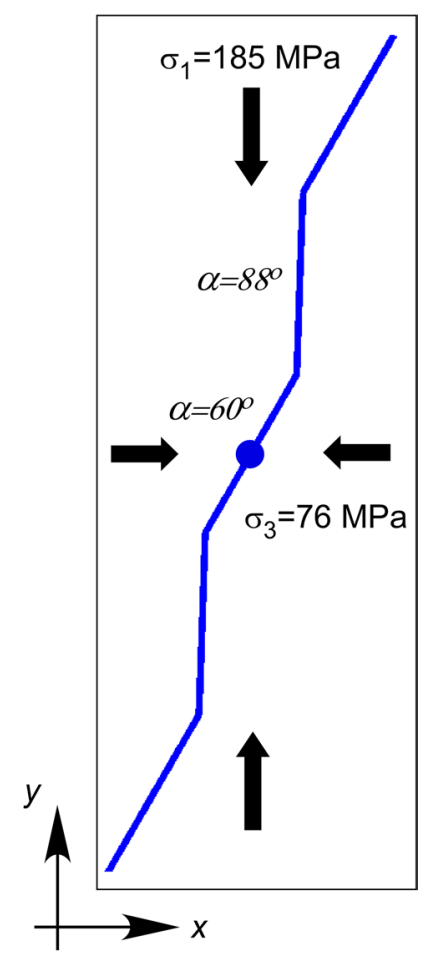

Fig. 2 Geometry of the "60-88" model. The blue line represents the fracture configuration and the blue dot the injection point. Each fracture segment is $60-\mathrm{m}$ long. Orientation and values of principal stresses are indicated

fluid injection (Garagash and Germanovich 2012; Gischig 2015; Piris et al. 2017). Fractures at $\alpha=60^{\circ}$ are characterised by a critically loaded behaviour, with high associated seismicity and ruptures that can propagate through the entire fracture. Fractures at $\alpha=88^{\circ}$ are characterised as having an aseismic orientation, with slow sliding velocities and are, thus, unable to produce seismicity (e.g. Piris et al. 2017).

Fluid injection was performed at the centre of the model. To evaluate the influence of the orientation of fractures in which the fluid was injected, two types of models were investigated: (1) the model named "60-88" in which the segment chosen for injection had an orientation of $\alpha=60^{\circ}$ (as shown in Fig. 2) and (2) the model "88-60" in which the segment where the fluid was injected was oriented at $\alpha=88^{\circ}$. Finally, we carried out additional simulations on a modified version of the "60-88" model to evaluate the effect of pressure drops with the propagation of hydraulic fractures. In such models (termed model "60-hydro"), we combined $\alpha=60^{\circ}$ segments with hydrofractures (i.e. tensile opening fractures) as wing cracks. In terms of numerical simulation, the main differences between the simulation setup of a pre-existing fracture or wing crack models are that (1) the tensile strength has to be overcome to initiate the wing crack and (2) the rate of fracture generation or propagation is determined by calculating a stress intensity factor at the fracture tips. This approach is similar to that used by other authors who modelled hydrofracture stimulation (McClure 2014; Zeeb and Konietzky 2015; Meyer et al. 2017). A summary of the mechanical parameters used in this study is shown in Table 1. 
Table 1 Friction and fracture parameters used in the simulations

\begin{tabular}{|c|c|c|c|}
\hline Parameter & Description & Value & Source \\
\hline$E_{0}$ & Mechanical aperture & $1200 \mu \mathrm{m}$ & \multirow{3}{*}{$\begin{array}{l}\text { Arbitrary (common values) (McClure 2012; } \\
\text { Gischig 2015) }\end{array}$} \\
\hline$\sigma_{\text {Enref }}$ & $\begin{array}{l}\text { Reference normal traction (mechanical } \\
\text { aperture) }\end{array}$ & $25 \mathrm{MPa}$ & \\
\hline$E_{\text {res }}$ & Residual mechanical aperture & $2 \mu \mathrm{m}$ & \\
\hline$\varphi_{\text {Edil }}$ & Dilatation angle (mechanical aperture) & $0^{\circ} / 2.5^{\circ} / 5^{\circ}$ & $\begin{array}{l}\text { (Willis-Richards et al. 1996; Kohl and Mégel } \\
\text { 2007) }\end{array}$ \\
\hline$e_{0}$ & Hydraulic aperture & $120 \mu \mathrm{m}$ & \multirow{3}{*}{$\begin{array}{l}\text { Arbitrary (common values) (McClure } 2012 \\
\text { Gischig 2015) }\end{array}$} \\
\hline$\sigma_{\text {enref }}$ & $\begin{array}{l}\text { Reference normal traction (hydraulic } \\
\text { aperture) }\end{array}$ & $25 \mathrm{MPa}$ & \\
\hline$e_{\text {res }}$ & Residual hydraulic aperture & $0.2 \mu \mathrm{m}$ & \\
\hline$\varphi_{\text {Edil }}$ & Dilatation angle (hydraulic aperture) & $2.5^{\circ}$ & Arbitrary (good coupling) \\
\hline$\rho$ & Fluid density & $1000 \mathrm{~kg} / \mathrm{m}^{3}$ & \multirow[t]{2}{*}{ Water values at $20^{\circ} \mathrm{C}$} \\
\hline$\mu$ & Fluid viscosity & $0.001 \mathrm{~Pa} \mathrm{~S}$ & \\
\hline$h$ & Out-of-plane dimension & $100 \mathrm{~m}$ & To obtain representative magnitudes \\
\hline$\eta$ & Radiation damping coefficient & $3 \mathrm{MPa} /(\mathrm{m} / \mathrm{s})$ & Arbitrary (common value) (McClure 2012) \\
\hline$S_{0}$ & Cohesion & $0 \mathrm{MPa}$ & Assumption \\
\hline G & Shear modulus & $15 \mathrm{GPa}$ & Arbitrary (common value) \\
\hline$v_{r}$ & Poisson's ratio & 0.25 & Arbitrary (common value) \\
\hline$f_{0}$ & Nominal friction coefficient & 0.85 & $\begin{array}{l}\text { Arbitrary (common value) (Häring et al. } \\
\text { 2008; Gischig 2015) }\end{array}$ \\
\hline$d_{c}$ & Characteristic displacement scale & $100 \mu \mathrm{m}$ & $\begin{array}{l}\text { Gouge material (Marone and Scholz 1988; } \\
\text { Scholz 2002; Gischig 2015) }\end{array}$ \\
\hline$a$ & Velocity effect coefficient & 0.01 & \multirow[t]{2}{*}{ Scholz (2002) } \\
\hline$b$ & State effect coefficient & 0.02 & \\
\hline$v_{0}$ & Reference velocity & $10^{-6} \mathrm{~m} / \mathrm{s}$ & Arbitrary (common value) \\
\hline$\theta_{\mathrm{RS}}$ & State & $2.6 \cdot 10^{6} \mathrm{~s}$ & Rubin and Ampuero (2005); Gischig (2015) \\
\hline$T_{\text {str }}$ & Matrix tension strength & $3 \mathrm{MPa}$ & Arbitrary (common value)(McClure 2014) \\
\hline$K 1_{\text {crithf }}$ & Stress intensity factor & $1.5 \mathrm{MPa} \mathrm{m} \mathrm{m}^{1 / 2}$ & $\begin{array}{l}\text { Arbitrary (common value)(Zeeb and Koni- } \\
\text { etzky 2015; Meyer et al. 2017) }\end{array}$ \\
\hline
\end{tabular}

For all the models, the geothermal reservoir was assumed to be at a depth of $4500 \mathrm{~m}$, with an initial fluid pressure defined by the hydrostatic gradient. We assumed a strikeslip regime in which the principal stresses $\sigma_{1}$ and $\sigma_{3}$ are horizontal (parallel to the $y$-and $x$-axis of our model, respectively; Fig. 2) while $\sigma_{2}$ is vertical (i.e. oriented out-of-plane in the models). A minimum in situ stress of $76 \mathrm{MPa}$ was imposed in the $x$-direction, while a maximum horizontal stress of $185 \mathrm{MPa}$ was applied in the $y$-direction. A constant injection pressure of $70 \mathrm{MPa}$ was imposed, with a maximum injection rate of $10 \mathrm{~kg} / \mathrm{s}$. The duration of simulation was set to be high enough to pressurise almost the entire domain $(t=50,000 \mathrm{~s})$.

A series of additional models were run to evaluate the influence of key parameters on the pressure drop phenomenon. These include the dilatancy effect, the scale effect and the model setup similar to that of the Rittershoffen geothermal reservoir. To evaluate the sensitivity of the models to the mechanical dilation angle (i.e. the dilatancy effect, defined as the increase of fracture volume by shear displacement), additional models were run with dilation angles $\left(\phi_{\text {Edil }}\right)$ of $2.5^{\circ}$ and $5^{\circ}$. The potential sensitivity of the length scale was evaluated in the model "88-60" using fracture segments with lengths of $50 \mathrm{~m}$, $40 \mathrm{~m}, 30 \mathrm{~m}, 20 \mathrm{~m}, 15 \mathrm{~m}$, and $6 \mathrm{~m}$. Finally, with the aim of comparing numerical predictions with field observations of seismicity coupled with pressure drops, several models 
with different length scales (i.e. $80 \mathrm{~m}, 60 \mathrm{~m}, 50 \mathrm{~m}, 40 \mathrm{~m}, 30 \mathrm{~m}, 20 \mathrm{~m}, 15 \mathrm{~m}$ and $6 \mathrm{~m}$ ) were run using a configuration similar to that utilised during the stimulation of the Rittershoffen geothermal reservoir (Cornet et al. 2007; Baujard et al. 2017; Meyer et al. 2017). For these models, the parameters that were varied with respect to the previous ones were the stress state $\left(\sigma_{1}=50 \mathrm{MPa}, \sigma_{3}=29 \mathrm{MPa}\right)$, the initial fluid pressure of $23.7 \mathrm{MPa}$ and a constant injection pressure of $28 \mathrm{MPa}$.

\section{Results}

The main parameters analysed in our simulations were the fluid pressure evolution, the fracture apertures, the earthquake hypocentre locations, and the earthquake magnitudes. These parameters were used to highlight differences between models.

\section{Model "88-60"}

The evolution of fluid pressure, fracture aperture and hypocentre locations are shown in Fig. 3. Microseismicity was observed in both segment orientations, with magnitude events spanning up to $M=2.5$. The events with the highest magnitudes were systematically located along the $\alpha=60^{\circ}$ segments, while the segments oriented at $\alpha=88^{\circ}$ recorded lower-magnitude events (with maximum magnitudes of $M<1.5$ ). The fluid pressurisation of the fracture was not homogeneous, with several abrupt events in which fluid pressure
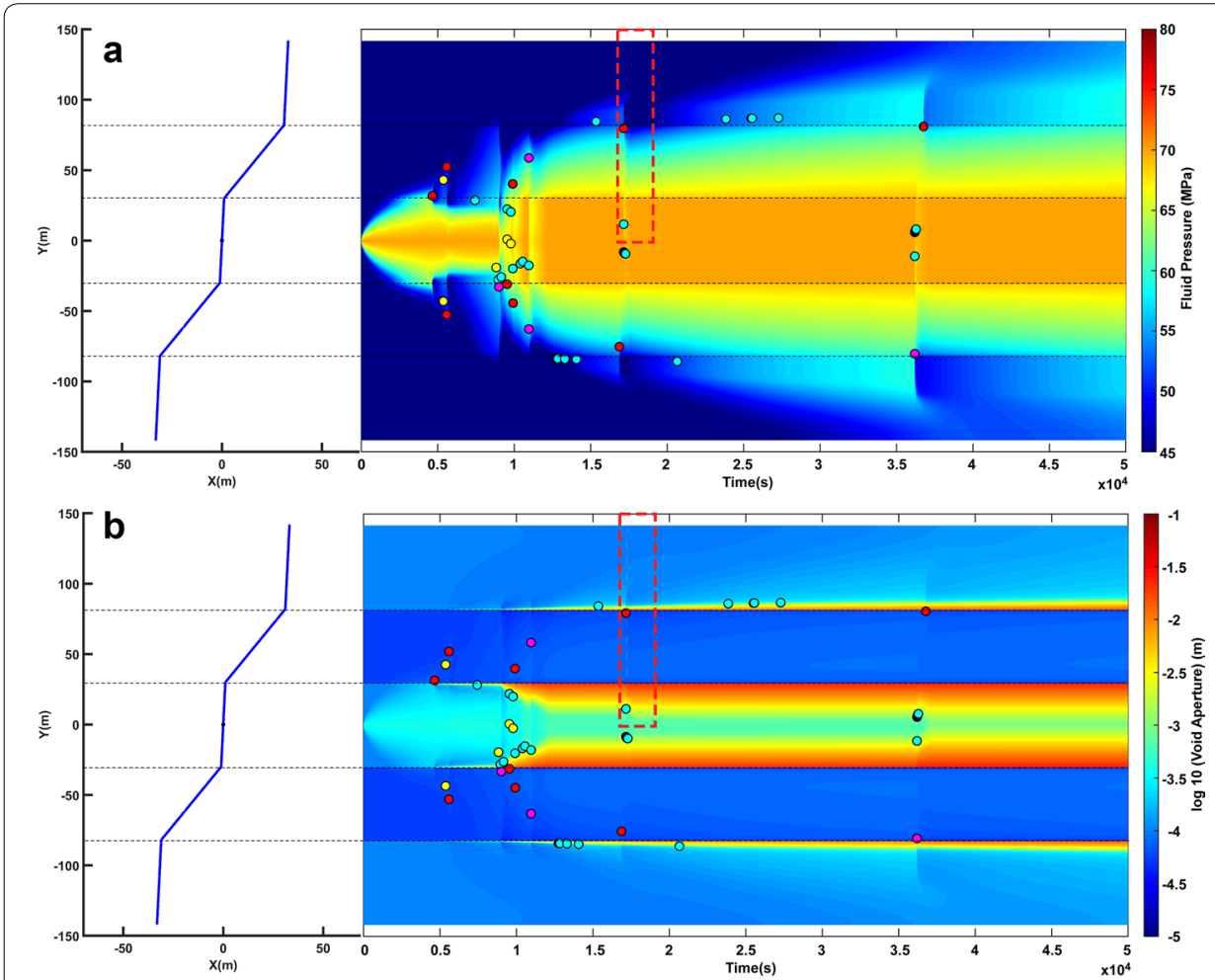

Fig. 3 Sketches of the simulated fracture network (blue lines on the left), and the evolution of a fluid pressure and $\mathbf{b}$ fracture aperture for the model " $88-60$ ". Dashed lines indicate the location of fracture segment intersections. Coloured points indicate the location of the earthquake hypocentres and magnitudes (cyan: $M<0$, green $0 \leq M<1$, yellow: $1 \leq M<1.5$, red: $1.5 \leq M<2$ and pink: $M \geq 2$ ). The red dashed area indicates the data shown in Figs. 5 and 6 

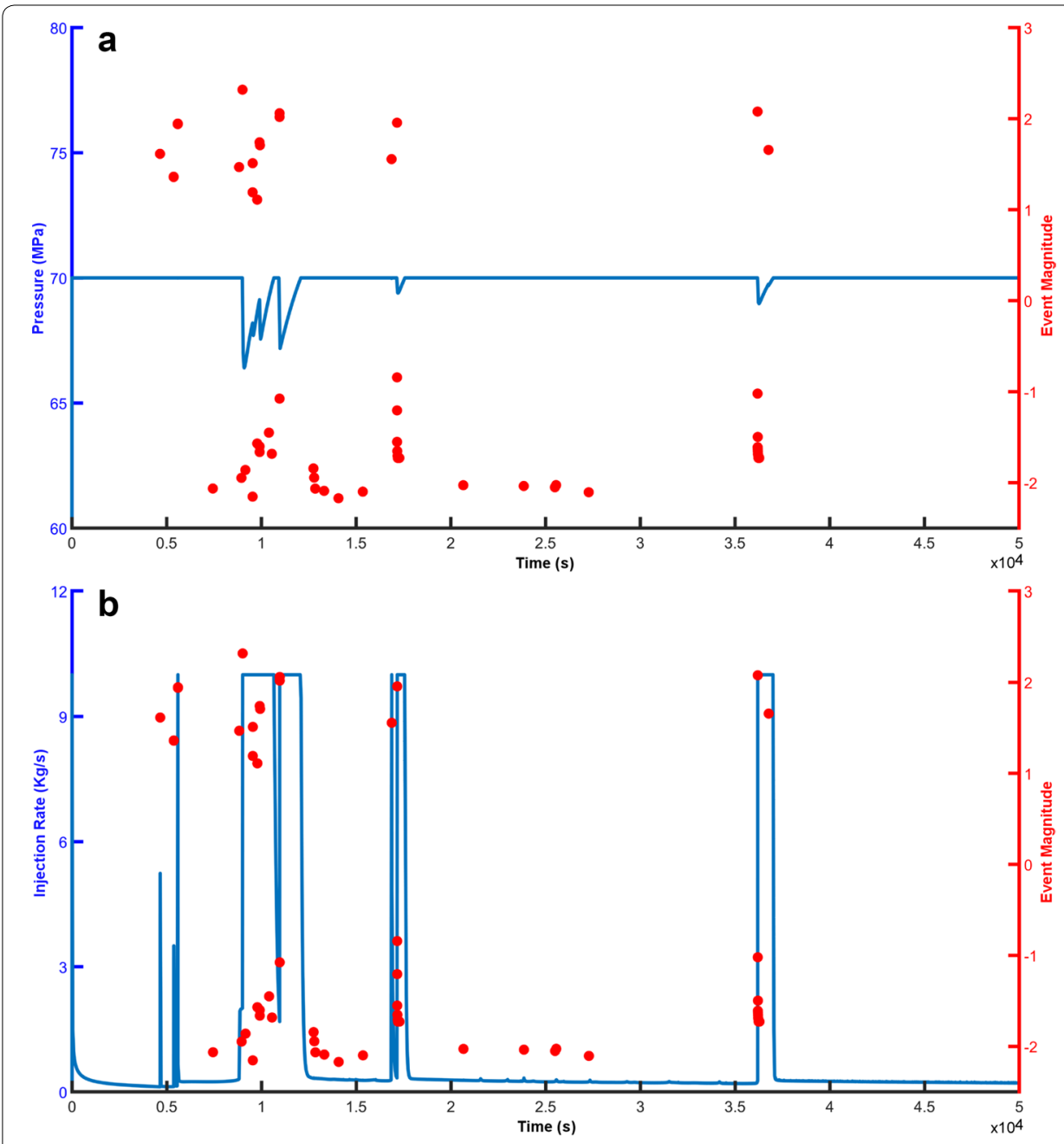

Fig. 4 Variation of the $\mathbf{a}$ fluid pressure in the well and $\mathbf{b}$ the injection rate with increasing stimulation time. The magnitude of the seismic events is indicated by red circles. In general, events with larger magnitudes are linked to fluid pressure drops in well, although a swarm of low-magnitude earthquakes is observed after pressure drops. Additionally, pressure drops are linked to peaks of the injection rate

drops were linked with seismic events. Initially, the fluid batch expanded homogenously along the $\alpha=88^{\circ}$ segment until it reached the intersection between two fracture segments. Seismic events and local pressure drops were generated from this point. Most of the hypocentres were located next to the intersection between fracture segments and near the pressurisation front. However, low-magnitude events were also observed in the central part of the model, along the $\alpha=88^{\circ}$ segment. With progressing injection, the fluid reached the following fracture intersections and hypocentres, thus, shifted to these regions. Larger-magnitude events $(M>1.5)$ were able to produce stronger pressure drops able to be transmitted along the entire fracture system, and thus being ultimately detectable at the well (Fig. 4a). Pressure drops in the well ranged between 0.5 and $3 \mathrm{MPa}$. Furthermore, pressure drops felt in the well were correlated with increases in injection rate due to permeability enhancement (Fig. 4b). The time lapse between the main earthquake event and the associated well pressure drop was found to be lower than $2 \mathrm{~s}$. This time 


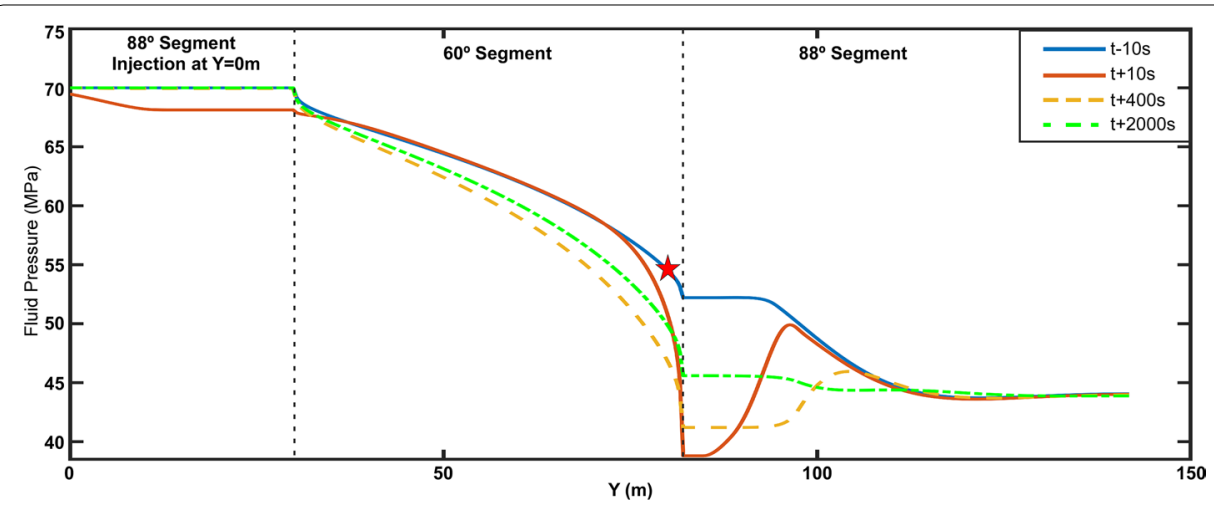

Fig. 5 Fluid pressure evolution with the distance to the well ( $Y$ ) before ( $t-10 \mathrm{~s})$ and after ( $t+10 \mathrm{~s}, t+400 \mathrm{~s}$ and $t+2000$ s) a seismic event (indicated by a red star) for the "88-60" model. The event corresponds to the red dashed area indicated in Fig. 3. Vertical dashed lines indicate the location of fracture segment intersections

lapse increases with the distance from hypocentre to the well. The evolution of fracture apertures was characterised by two stages. In the early stage, before the stimulation of $\alpha=60^{\circ}$ segments, fracture apertures increased from the well in the same direction as that of the migration of the fluid pressure front $\left(t<0.5 \times 10^{4} \mathrm{~s}\right.$; Fig. $\left.3 \mathrm{~b}\right)$. In the second stage, after stimulation of the $\alpha=60^{\circ}$ segments, fracture apertures expanded from fracture intersections towards the well, in a direction opposite to that of the expansion of the fluid pressure front. The highest observed apertures corresponded to the $\alpha=88^{\circ}$ fractures, with values reaching $0.027 \mathrm{~m}$, while apertures slightly increased for $\alpha=60^{\circ}$ segments.

Snapshots of the fluid pressure before $(t-10 \mathrm{~s}$, where $t$ is the time of the main seismic event) and after ( $t+10, t+400$ and $t+2000 \mathrm{~s})$ the main seismic event of $M=1.96$ (indicated by the red dashed line in Fig. 3) are shown in Fig. 5. Strong variations of fluid pressure were observed before the onset of the seismic event near the intersection between segments. At $t+10 \mathrm{~s}$ after the seismic event, a strong fluid pressure decrease was observed in the intersection segment and along $\alpha=88^{\circ}$ segment fractures. With increasing time $(t+400 \mathrm{~s}$ and $t+2000 \mathrm{~s}$ in Fig. 5), the fluid pressure recovered quickly in the injection segment next to the well, while fluid pressure recovery was slow in the rest of the fracture, especially at the intersection near the location of the seismic event.

The evolution of fracture aperture is displayed for the same event in Fig. 6 for several control points next to the fracture intersections. Fracture apertures showed different trends depending on the distance to the intersections, and an aperture increase was not always observed for all monitoring points. While fracture apertures at the points located at the seismic segment remained approximately constant or slightly decreased (points 3 and 4 in Fig. 6), the evolution of apertures for the $\alpha=88^{\circ}$ segment showed aperture increases for control points next to the intersections (points 2 and 5 in Fig. 6). Apertures initially decreased and then increased (or remained constant) for control points located away from the intersections (points 1 and 6 in Fig. 6).

\section{Model "60-88"}

Fluid pressure and fracture aperture evolution through time are shown in Fig. 7. In this case, the well was located at a critical seismic fracture $\left(\alpha=60^{\circ}\right)$. Microseismicity was 


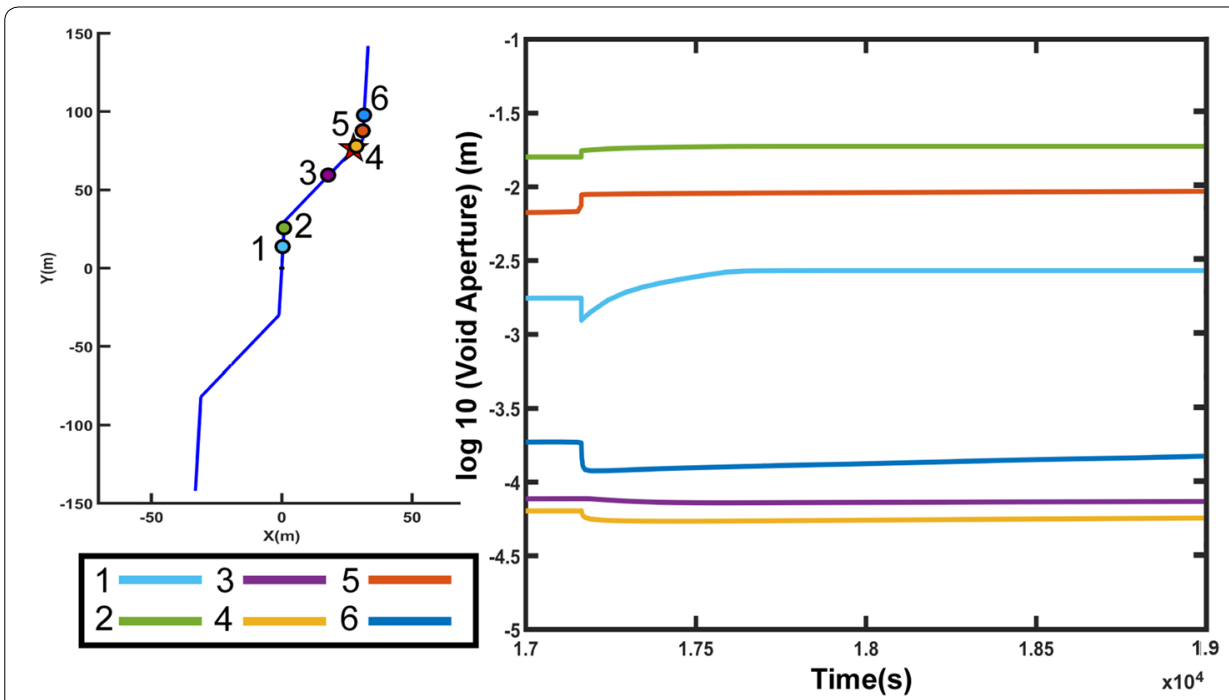

Fig. 6 Right, fracture network (in blue) and location of control points (coloured dots). Left, evolution of log 10 (void aperture) at the control points through time. The time interval and region monitored by control points is indicated with the red dashed area in Fig. 3. The hypocentre location is the same as that of Fig. 5

detectable from early stages of injection and expanded from the well towards the first fracture intersection (Fig. 7). Abrupt decays of fluid pressure were linked with seismicity, although they did not produce detectable pressure drops at the well. In general, microseismic events occurred near the intersection regions, although several low-magnitude events were observable in the $\alpha=88^{\circ}$ fractures behind the pressurisation front. Progression of the fluid along the fracture produced a migration of hypocentres until they reached the intersection of the last fracture, producing a large batch of events with strong ruptures (Fig. 7, at approx. $t=4.5 \times 10^{4} \mathrm{~s}$ ). The evolution of fracture apertures showed similar patterns as in the previous case (88-60 model), with the maximum apertures propagating from fracture intersections following the aseismic $\alpha=88^{\circ}$ fractures (Fig. 7b).

The event with magnitude $M=2.1$ and hypocentre in the $\alpha=60^{\circ}$ segment was analysed for the model "60-88" (Figs. 8, 9) (red dashed line in Fig. 7). In general, fluid pressure curves and patterns are similar to those of the previous case (Fig. 8). For this configuration, the pressure drop was not felt at the well (Fig. 8). The aperture evolution was not homogenous and control points generally showed a decrease of the fracture aperture. Aperture increases occurred only next to the intersection and along the $\alpha=88^{\circ}$ segment (point 3 in Fig. 9), followed by a region where the aperture decrease was followed by a constant increasing value (point 2 in Fig. 9).

\section{Model "60-hydro"}

Figure 10 shows the evolution of fluid pressure, fracture aperture and microseismic event magnitude and location of the model defined by a pre-existing fracture with two potential tensile cracks at their tips (i.e., wing cracks; red lines in Fig. 10). As in previous models, the events with higher magnitudes were located at the pre-existing segment 


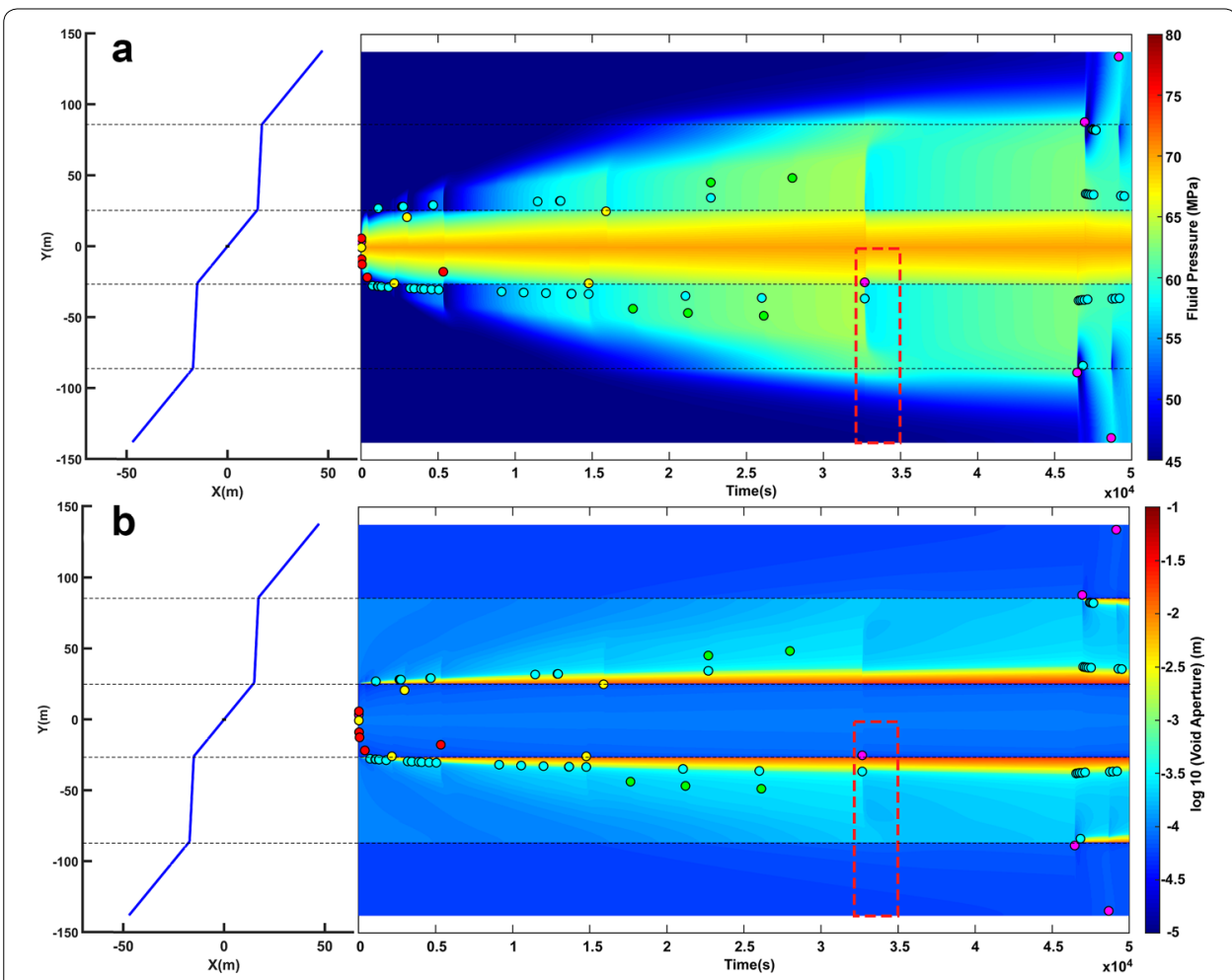

Fig. 7 Sketches of the simulated fracture network (blue lines on the left graphs), and the evolution of a fluid pressure and $\mathbf{b}$ fracture aperture for the model "60-88". Dashed lines indicate the location of fracture segment intersections. Coloured points indicate the location of the earthquake hypocentres and magnitudes (cyan: $M<0$, green $0 \leq M<1$, yellow: $1 \leq M<1.5$, red: $1.5 \leq M<2$ and pink: $M \geq 2$ ). The red dashed area indicates the data shown in Figs. 8 and 9

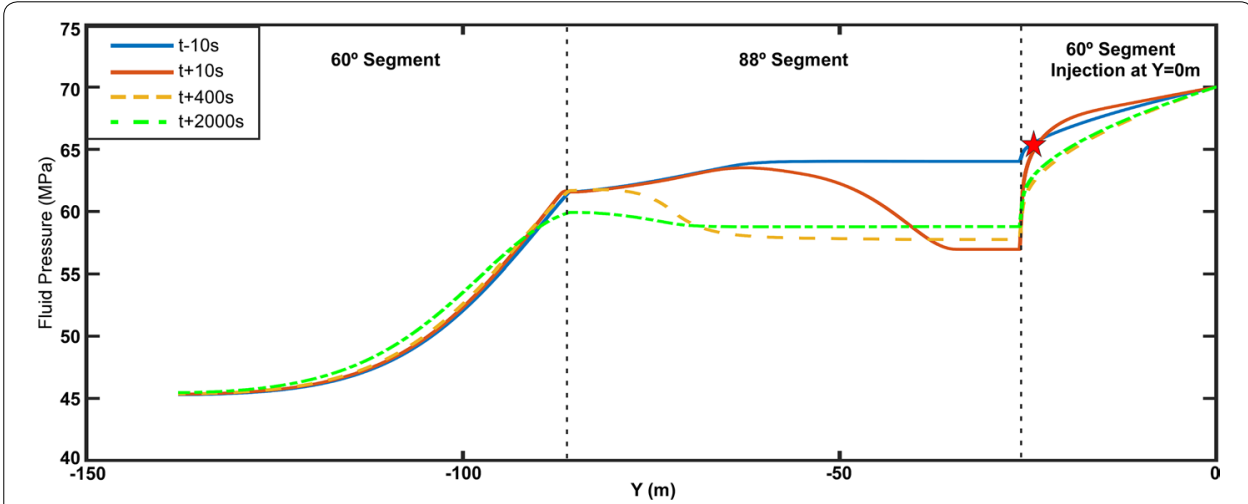

Fig. 8 Fluid pressure evolution depending on distance to the well $(Y)$ before $(t-10 \mathrm{~s})$ and after $(t+10 \mathrm{~s}$, $t+400 \mathrm{~s}$ and $t+2000 \mathrm{~s}$ ) a large-magnitude seismic event (red star, $M=2.1$, red dashed rectangle in Fig. 7 ) for the "60-80" model. Vertical dashed lines indicate the location of intersections between fracture segments

$\left(\alpha=60^{\circ}\right)$, while wing cracks only registered low-magnitude events linked to the propagation of the fluid pressure front. The propagation of this front along wing cracks was relatively slow compared to previous models with pre-existing fractures (models "88-60" or "60-88"). Pressure drops were also identified and linked to seismic events at the $\alpha=60^{\circ}$ 


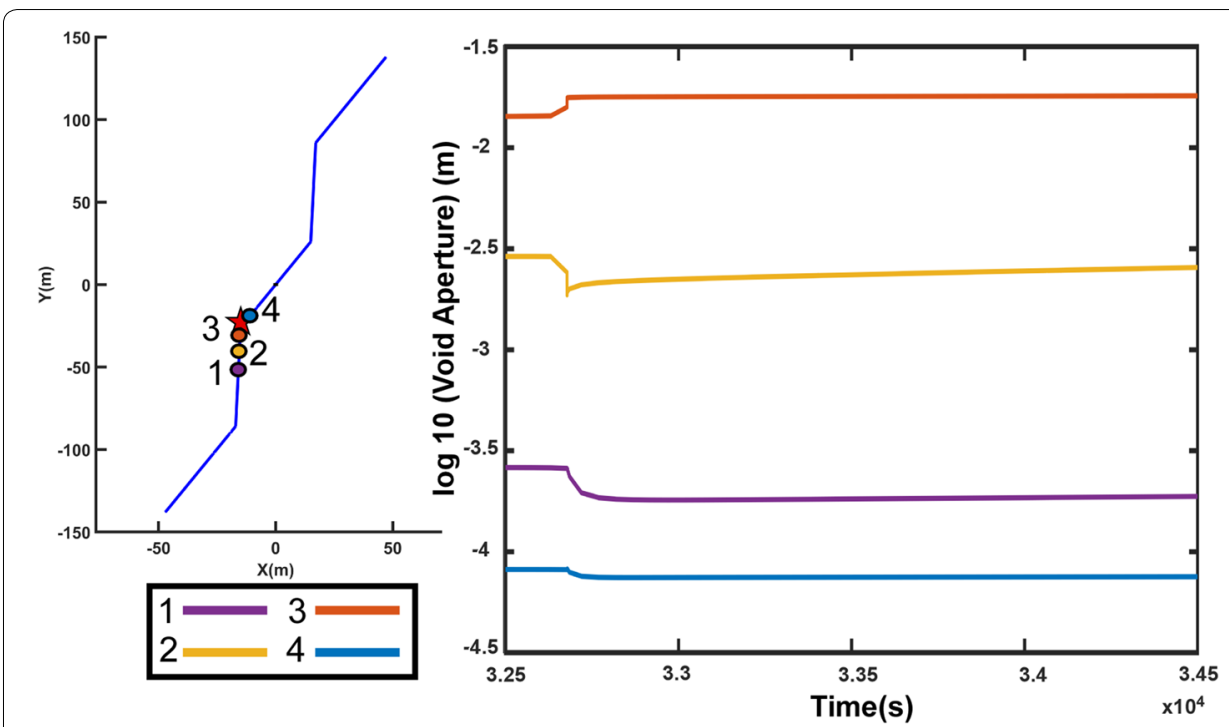

Fig. 9 Right, fracture network (in blue) and location of control points (coloured dots). Left, evolution of log 10 (void aperture) of the control points through time. The interval of time and region monitored by control points is the red dashed area shown in Fig. 7. The hypocentre location is the same than in Fig. 8

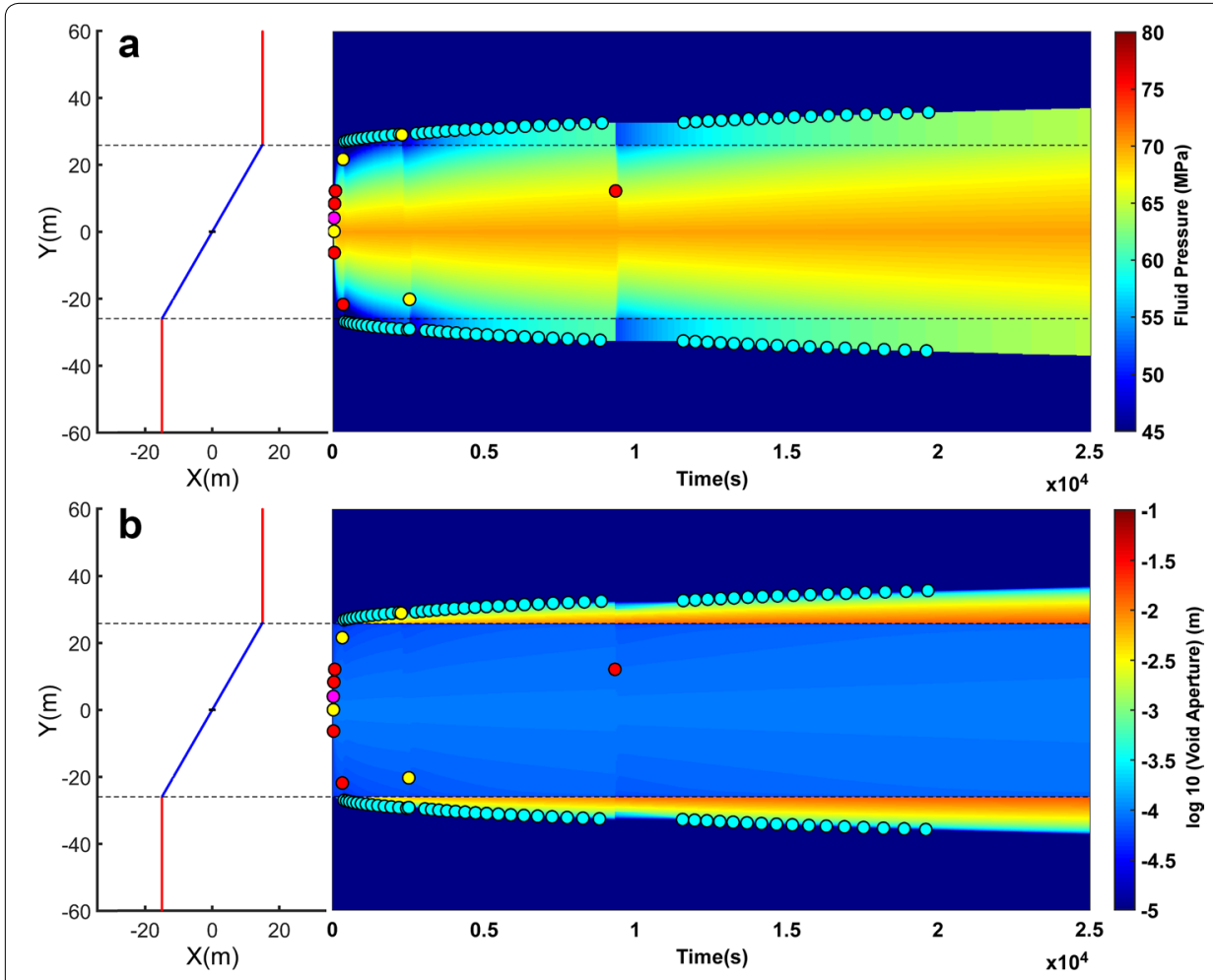

Fig. 10 Sketch of the fracture network on the left (the blue line is the pre-existing fracture and red lines represent the wing cracks) and evolution of $\mathbf{a}$ fluid pressure and $\mathbf{b}$ fracture aperture. Black dashed lines indicate the fracture segment intersection points. The coloured points indicate the seismic hypocentres and their magnitudes (cyan: $M<0$, green $0 \leq M<1$, yellow: $1 \leq M<1.5$, red: $1.5 \leq M<2$ and pink: $M \geq 2$ ) 

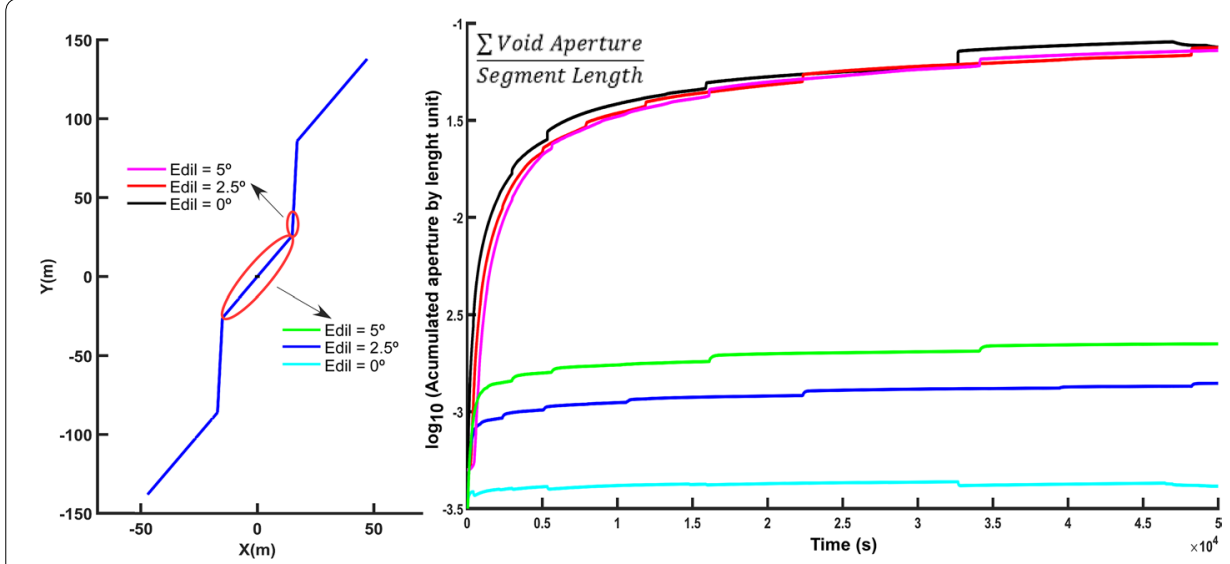

Fig. 11 Accumulated aperture by length unit in the injection seismic segment and in the opening region of the aseismic segment with different dilation angles $\left(0^{\circ}, 2.5^{\circ}\right.$ and $\left.5^{\circ}\right)$ for the " $60-88^{\prime \prime}$ model

segment (Fig. 10 at around $t=1 \times 10^{4} \mathrm{~s}$ ). The widest fracture apertures were observed along wing cracks, while the aperture of the natural fracture slightly increased.

\section{Sensitivity analysis}

All the model configurations (i.e. models " $88-60$ ", "60-88" and "60-hydro") were run with different values of mechanical dilation angles $\left(\phi_{\mathrm{Edil}}=0^{\circ}, 2.5^{\circ}\right.$ and $\left.5^{\circ}\right)$ to test their influence on fracture aperture and pressure drops. The cumulative apertures increased half an order of magnitude in the seismic segments $\left(\alpha=60^{\circ}\right)$ when large dilation angles were used, while apertures only slightly increased in the aseismic segments $\left(\alpha=88^{\circ}\right)$ (Fig. 11). The total aperture change (normalised by length) was between two and oneand-a-half order of magnitude higher in the aseismic segment than that produced in the seismic segment (Fig. 11). The sharp steps of the accumulated aperture in Fig. 11 correlate with seismic events, while slight and progressive fracture aperture increases characterise the progressive aseismic deformation.

The dilatation angle also plays a secondary role in the occurrence of pressure drops at the well and in the bulk model (Fig. 12a). This tendency depends on the geometrical configuration of the model. While in the " $88-60$ " model configuration, there was a pressure drop decrease at the well with increasing dilatation angles (from an average of 1.25 to $0.4 \mathrm{MPa}$ ), in the "60-88" models, the tendency was the opposite, in a way that pressure drops raise with increasing dilatation angles (from 0 to $1 \mathrm{MPa}$ on average). The "60hydro" model followed a similar tendency to that observed in the "60-88" model.

Finally, the influence of the length scale of the fracture segments on the pressure drops is summarised in Fig. 12b. Using as a reference the model "88-60" and $\phi_{\text {Edil }}=0^{\circ}$, different runs were carried out with different segment sizes $(60 \mathrm{~m}, 50 \mathrm{~m}, 30 \mathrm{~m}, 20 \mathrm{~m}, 15 \mathrm{~m}$, and $6 \mathrm{~m}$ ). Systematic pressure drops in the well and in the entire domain were identified and the mean values were calculated. There was a systematic decrease of the pressure drop values throughout the system with decreasing segment length (from $6 \mathrm{MPa}$ for the 60-m-length model to 1.5 MPa for the 6-m model). Pressure drop values in the well were very similar, although there was an increase of ranging between 30 and $15 \mathrm{~m}$ (Fig. 12b). 

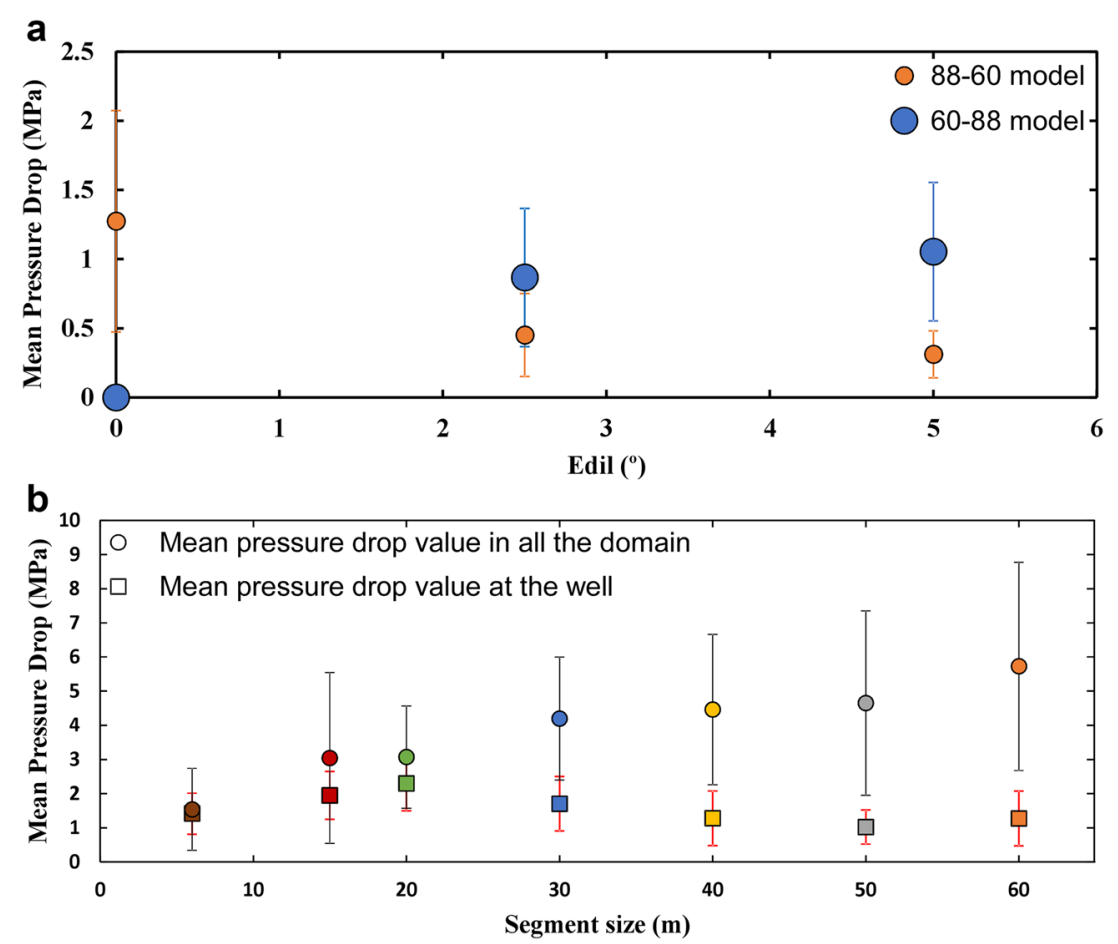

Fig. 12 a Mean well pressure drops against different mechanical dilatation angles for the " $88-60$ " and "60-88" configuration models. $\mathbf{b}$ Mean pressure drop values observed for all the simulation domain (circles) and felt at the well (squares) for different segment sizes. Error bars indicate the standard deviation

\section{Discussion}

\section{Pressure drop mechanism}

The results of our numerical simulations demonstrate that a direct link between seismicity and pressure drops can be established. The formation of pressure drops seems to be related to the activation of slip along a pre-existing fracture during seismic events in regions near fracture intersections. This process operates in a series of steps summarised in Fig. 13.

In situations where the fluid is injected in a fracture segment at a low angle with $\sigma_{1}$ (e.g. model " $88-60$ "), the fracture high fluid storage capacity or transmissibility allows it to be initially pressurised without seismicity. Once the pressure front reaches the intersection between fracture segments, and a seismic segment is stimulated, microseismicity occurs. When the tensile strength is overcome in the seismic segment (i.e., $\alpha=60^{\circ}$ ), the fracture slides and the relative displacement between walls induces stress concentration at fracture tips. In our models, this stress was high enough to open the tensional segments, producing a slight decrease of fluid pressure next to the intersection zones (for example see Fig. 3 around $t=0.5 \times 10^{4} \mathrm{~s}$ ). After that, a time lapse is required to re-pressurise the region prior to the onset of a new pressure drop. This pressurisation is followed by new seismic events that assist the opening of additional tensional segments. These processes are repeated until all the seismic segments are completely stimulated. While the injected fluid progressively flows from the well throughout the fracture network, seismic events migrate from intersections located next to the injection well to more distant ones. 


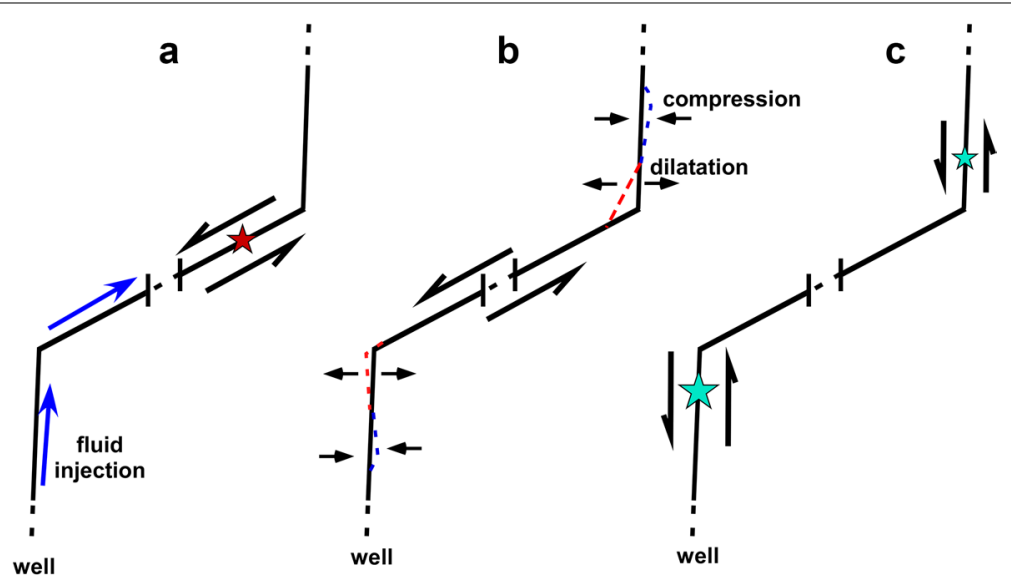

Fig. 13 Sketch representing the different processes involved in a fluid pressure drop. a Start of the pressure drop process, in which a seismic event is produced at the seismic segment (red star), with arrows indicating the sliding direction. b Dynamic aperture (red dashed lines) and closure (blue dashed lines) on the aseismic tips connected with the seismic segment. c Low-magnitude events at the aseismic tips occur to accommodate the opening generated. Seismicity is higher in the already pressurised segment than in the new stimulated segment (blue stars)

Tensional segments are stimulated as aseismic segments or result in seismic events with very low magnitude. Larger events are located along seismic fractures and tend to occur near the intersections. With ongoing stimulation, seismic events progressively occur at longer distances from the injection point and the induced pressure drops are, thus, hardly observable by looking at the fluid pressure measured at the well. Nevertheless, they are continually happening, as illustrated in Figs. 3, 7 and 10 or in Fig. 12b, in which the difference between pressure drops at the well and in the simulation domain increases with increasing of fracture length.

In cases where fluid injection is carried out in a low-transmissivity fracture segment (model "60-88"; Fig. 7), pressure drops are difficult to be detected at the injection point. The fracture acts as a barrier for the pressure drop propagation due to its low storage capacity and low hydraulic aperture. The process producing pressure drops operates in a similar way as in the model previously described. When the tensile strength is overcome in a seismic segment, a sudden aperture change of the intersection is induced, causing the aseismic/tensional segments (i.e., high-capacity fractures) to get open, generating a new volume and producing the pressure drop (for example, see those at $t \sim 3.25 \times 10^{4} \mathrm{~s}$ in Figs. 7, 8 and 9 or between $t=4$ and $4.5 \times 10^{4} \mathrm{~s}$ in Fig. 7).

Another process associated with void aperture can be detected when pressure drops are analysed in detail (Figs. 5, 6, 8 and 9). The opening of aseismic fractures was not homogenous in our models, and regions along the same fracture segment experienced closing and opening during stimulation of the fracture intersections. Some regions are opened suddenly, while others are closed suddenly (e.g. points 1 and 6 in Fig. 6). Since a sudden fracture opening should imply a pressure drop, its sudden close should be associated with a local fluid pressure rise. Such local pressure rises, which get quickly dissipated, are likely to be felt more intensively in low-permeability 
fractures, i.e. in fractures that are shear stimulated (this can be detected for example in the curve $t+10 \mathrm{~s}$ in Fig. 8 for injection in the $60^{\circ}$ segment).

Models " $60-88$ " and " $88-60$ " were carried out to explore the influence of the orientation of the fracture in which the fluid was injected. Despite the initial differences between the two models, their dynamic behaviour is very similar, and both show similar pressure drop phenomena. Similarly, the variation of the dilation angle or the length scale does not modify the described processes, but only determines the absolute values of pressure drops (Fig. 12) and the magnitude of microseismicity. Increasing the dilatational angle produces a permeability increase in the shear-stimulated fractures, allowing the propagation of pressure drops up to the well (Fig. 12a). However, the pressure drop process is similar to that in models "60-88" and " $88-60$ ", and is related to the reactivation by sliding of a shear-stimulated fracture and the opening of the tensile conjugated fractures. Figure 13 shows a synthesis of the processes related to pressure drops. The influence of the injection rate was tested (from $2 \mathrm{~kg} / \mathrm{s}$ up to $100 \mathrm{~kg} / \mathrm{s}$ ), producing a reduction of pressure drop values. However, the main pressure drop values in the system are independent of this parameter.

The same pattern was observed in the model with wing cracks (model "60-hydro"). When the seismic segment is stimulated, the wing crack is forced to open, producing a pressure drop and enhancing its propagation. In our simulations, pressure drops were not related to wing crack propagation, which was associated with the stress concentration at the edges of the pre-existing fracture. Sliding of the seismic segment allowed wing crack propagation, given that injection pressure in our models was lower than the minimum principal stress $\left(\sigma_{3}\right)$. This resulted in hydrofracture propagation with injection fluid pressures below $\sigma_{3}$ and in accordance with the model proposed by McClure and Horne (2014), as an explanation of the mixed-mechanism stimulation for EGS projects (i.e., shear stimulation operates jointly with new tensile fracture generation).

As previously mentioned, Meyer et al. (2017) concluded that pressure drops could be produced by the propagation of tensile fractures as a wing crack. This process could be interpreted in a similar way, as observed in breakdown tests and used to identify the minimum principal stress (Prabhakaran et al. 2017). In these tests, the generation of a new hydrofracture produces a pressure drop because the fluid quickly migrates into the newly formed fracture, oriented normal to the minimum stress. However, the process of hydraulic fracture propagation as a wing crack due to the stress concentration at fracture tips was achieved under conditions of fluid pressure below $\sigma_{3}$. According to the modelling parameters used in our simulations (specifically the injection fluid pressure and the tensile strength of the material), sudden changes as those observed in breakdown tests (in which the injection pressure reaches $\sigma_{3}$ ) are not observed. Moreover, as discussed above, pressure drops in our models are linked with the tensile fracture opening rather than its propagation, regardless of whether this fracture is a pre-existing or a newly formed one.

\section{Seismicity and pressure drops}

In terms of the seismicity associated with pressure drops, we can distinguish two types of events. The first type of seismic event is produced in the seismic segments by fluid 
pressurisation, acting as a trigger for the pressure drop phenomenon and usually producing high magnitudes $(M>1.5)$. The second type of seismic event is produced at the aseismic fracture segments next to the regions that are opening. Normally, the latter events appear as low-magnitude seismic swarms (events with magnitude below one or zero), produced to accommodate the displacement generated by the sliding of seismic segments and the opening of the aseismic ones. A similar behaviour can be observed in the model containing a pre-existing fracture combined with wing cracks. This duality of the system's seismicity was proposed and analysed by Fischer and Guest (2011). In their model, the higher magnitude events are located at the critically stressed natural fractures, while lower magnitudes occur at pre-existing tensile fractures or new hydrofractures. Such behaviour would be expected in a mixed-stimulation mechanism, where these different stimulation mechanisms operate jointly (McClure and Horne 2014; Norbeck et al. 2018).

A key aspect in our simulations is the tendency of microseismicity to cluster next to the intersections between fractures. The influence of intersections between fractures on the seismicity population and location was already proposed by Rutledge et al. (2004). Their interpretation of microseismicity generated during fluid stimulation in the Cartage Cotton Gas field (Texas) showed anomalous dense clusters of seismic events following intersections between fractures. Clusters showed location patterns diverging in time, progressively migrating from the injection zone to far away regions. Additionally, clustering of events was related to fewer and larger precursor events along critically stressed fractures, while other segments oriented at low angles to $\sigma_{1}$ experienced an aseismic behaviour. After injection shut-in, new large-magnitude and clustered seismic events were observed. This phenomenon was interpreted by Rutledge et al. (2004) as a result of fluid flow forced by slip-induced loading along critical seismic fractures. During injection, the increase of fluid pressure critically stimulated pre-existing fractures and fracture intersections, allowing fluid migration along the fracture network.

\section{Rittershoffen sensitivity analysis}

To evaluate the applicability of our results, stress drops and microseismicity data from the stimulation of the GRT1 well in Rittershoffen (Meyer et al. 2017) were analysed using a sensitivity analysis similar to that presented here. The stress and injection conditions used for these models are described in the Model Setup section. For this setup, pressure drops and seismic magnitudes are lower than those previously described, as stress magnitudes are substantially lower. The relationship between pressure drops mean values in the well and in the simulation domain with respect to the seismic magnitudes is shown in Fig. 14. Pressure drops were not detected at the well for fractures with length scales below $30 \mathrm{~m}$. The maximum was observed for 50-m-long fractures, while those longer than $80 \mathrm{~m}$ produced pressure drops that could hardly be detected at the well. As expected, a proportional relationship between the seismic magnitude and pressure drops in the system was observed. For the range of seismic magnitudes and pressure drops observed in the Rittershoffen case (box grey area in Fig. 14; from Meyer et al. 2017), we can infer that fracture sizes of stimulated fractures could range between 40 and $60 \mathrm{~m}$. A better constraint could potentially be obtained if pressure drop data were linked to magnitude and epicentre (unreported in Meyer et al. 2017), because in such case, the 


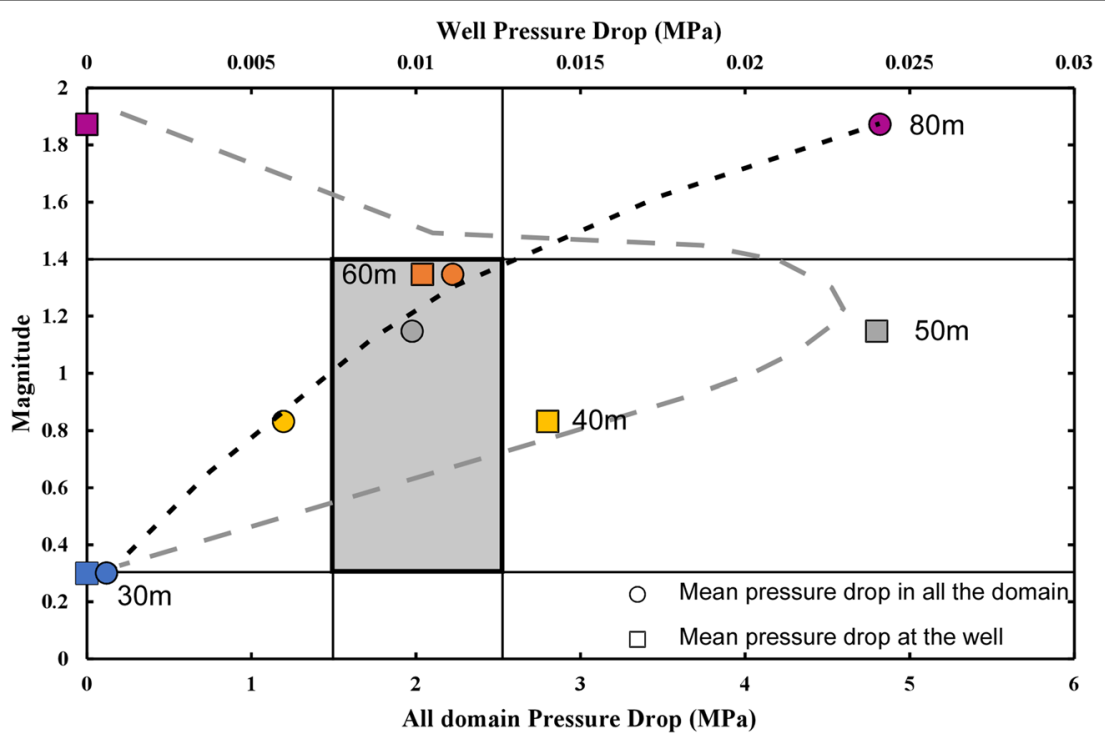

Fig. 14 Mean seismic magnitude against mean pressure drop in all the domain (circle symbols, lower $x$-axis) and at the well (square symbols, upper $x$-axis). Each colour represents a different segment size, ranging from 30 to $80 \mathrm{~m}$. Pressure drops were not observed in models with length size lower than $30 \mathrm{~m}$. The black dashed curve indicates the general tendency of pressure drops measured in all the domain, while the grey dashed curve represents the general tendency of pressure drops at the well. The dashed area indicates the range of pressure drops and seismic events observed during stimulation in the Rittershoffen reservoir (Meyer et al. 2017)

distance to the well could be utilised for the analysis. However, a handicap is that large uncertainty is normally associated with earthquake location data, normally longer than hundreds of metres (e.g., Kinnaert 2016).

Furthermore, our models show that the time lapse between the main earthquake event and the pressure drop at the well occurs after a few seconds (less than 2-4 s). This very short time interval probably implies that both phenomena will be almost simultaneously detected in real cases, requiring a highly precise time synchronisation between injection and seismicity data.

Our models use simplified geometries and are intended to help in investigating and understanding physical processes, rather than providing a perfect representation of reality. We chose not to use a model with complex multifracture networks, such as that utilised by Meyer et al. (2017), to isolate the main processes controlling pressure drops and seismicity. With a more complex network, the superposition of effects could attenuate the phenomena. Simulations by Meyer et al. (2017) with multifracture networks also produced pressure drops next to the intersections between fractures. However, their signal in the fluid pressure evolution at the well was attenuated. Additionally, there is a higher chance that more fractures can act as barriers to the propagation of transient variations of fluid pressure in multifracture systems. Our results confirm the interpretation by Meyer et al. (2017) that the conditions required to observe pressure drops in wells are very specific and unlikely to be observed in all reservoir formations. For injection wells located at a fracture with high transmissibility (i.e. model "88-60"), pressure drops at the well are potentially observable. However, pressure drops are hardly detectable in situations where the wells are located in low-transmissibility fractures (i.e. model "60-88"). 
However, as demonstrated by the numerical simulations presented here, pressure drops may occur in the reservoir even if they are not detected at the injection well.

Our simulations were carried out in isothermal conditions and, therefore, thermal drawdown effects are not modelled. In terms of stress reduction and seismicity, Gan and Elsworth (2014) observed that a second seismic cycle is developed related to the thermal drawdown that could potentially produce a second pressure drop cycle. It would be useful to repeat our analysis with a fully $3 \mathrm{D}$ model, since $2 \mathrm{D}$ models may enhance the magnitude of early events. Furthermore, the height used in our models (Table 1) is only an assumption required to take into account the third dimension, assuming plain strain for height values much larger than the fracture size (Shou and Crouch 1995).

\section{Conclusions}

Using simple fracture geometry configurations, we investigated different hypotheses for the occurrence of fluid pressure drops associated with hydraulic stimulation in Engineered Geothermal Systems (EGS). The results suggest that two fracture sets can influence pressure drops: one system able to be stimulated by shear (that will produce seismic events) and another one able to be stimulated by opening-mode fracturing (that will be aseismic). The tendency of stimulation by shear- or opening-mode fracturing is determined by the operational parameters (i.e. injection pressure, flow rate, etc.) and the stress state.

In the simulations, a pressure drop can be triggered by a seismic event in a shear-stimulated fracture that is hydraulically connected with a tensile or opening-mode fracture. The pressure drop is not produced by the new volume created by dilatancy, but by the opening of the conjugated tensile fracture instead.

This tensile fracture set may be part of the pre-existing fracture network, or alternatively, be developed as a hydrofracture during the stimulation phase. However, in our simulations, no pressure drops are observed during hydraulic fracture propagation at the tips of a preexisting fracture. Nevertheless, once wing cracks are created, it is possible that slip along the natural fracture causes a significant aperture change on the splay fracture that can result in a pressure drop. In addition, we show how seismicity propagates through fracture arrays while poorly oriented segments slip aseismically. Seismicity is concentrated in critically oriented fractures near fracture intersections. The pressurisation front propagates nonsmoothly and can be affected by the interaction of a conjugate fracture with other fractures with tensional or sliding properties. Our simulation results show that natural fracture/splay fracture interaction is a plausible explanation for the observed pressure drops at the Rittershoffen geothermal site.

\section{Authors' contributions}

This work is part of the Ph.D. project of GP. (corresponding author). GP designed and performed the numerical simulations, analysed the data and wrote the first draft of the manuscript; AG designed and supervised the study; EG-R and IH supervised and analysed the data. MM and JN developed the numerical code (CFRAC) used in this study. All authors read and approved the final manuscript.

\section{Author details}

${ }^{1}$ Departament de Geologia, Universitat Autònoma de Barcelona, 08193 Bellaterra (Cerdanyola del Vallès), Spain. ${ }^{2}$ Departament de Mineralogía, Petrología i Geología Aplicada, Universitat de Barcelona, 08028 Barcelona, Spain. ${ }^{3}$ School of Geosciencies, King's College, University of Aberdeen, Aberdeen AB24 3UE, UK. ${ }^{4}$ Institut Cartogràfic i Geològic de Catalunya (ICGC), Parc de Montjuic, s/n, 08038 Barcelona, Spain. ${ }^{5}$ ResFrac Corporation, Palo Alto, CA 94301, USA. ${ }^{6}$ Department of Energy Resources Engineering, Stanford University, Stanford, CA 94025, USA. ${ }^{7}$ Present Address: Earthquake Science Center, U.S. Geological Survey, Menlo Park, CA, USA. 


\section{Acknowledgements}

The Institut Cartogràfic i Geològic de Catalunya is acknowledged for their support in our investigation of Geothermal resources. G. Piris was supported by an AGAUR grant of the Industrial Doctorate programme 2016-DI-031. EGR acknowledges the support of the Beatriu de Pinós programme of the Government of Catalonia's Secretariat for Universities and Research of the Department of Economy and Knowledge (2016 BP 00208). The authors would like to thank three anonymous reviewers and the editors Dr. Carola Meller and Prof. Olaf Kolditz for their helpful comments that improved this manuscript.

\section{Competing interests}

The authors declare that they have no competing interests.

\section{Availability of data and materials}

All datasets generated during and/or analysed during the current study are available from the corresponding author on reasonable request.

\section{Funding}

G. Piris was supported by AGAUR grant for Industry Doctorate Research 2016-DI-031.

\section{Publisher's Note}

Springer Nature remains neutral with regard to jurisdictional claims in published maps and institutional affiliations.

Received: 16 March 2018 Accepted: 8 November 2018

Published online: 16 November 2018

\section{References}

Baujard C, Genter A, Dalmais E, Maurer V, Hehn R, Rosillette R, Vidal J. Hydrothermal characterization of wells GRT-1 and GRT-2 in Rittershoffen, France: implications on the understanding of natural flow systems in the Rhine graben. Geothermics. 2017;65:255-68. https://doi.org/10.1016/j.geothermics.2016.11.001.

Breede K, Dzebisashvili K, Liu X, Falcone G. A systematic review of enhanced (or engineered) geothermal systems: past, present and future. Geotherm Energy. 2013;1:1-27. https://doi.org/10.1186/2195-9706-1-4.

Cornet FH, Bérard T, Bourouis S. How close to failure is a granite rock mass at a 5 km depth? Int J Rock Mech Min Sci. 2007;44:47-66. https://doi.org/10.1016/j.ijrmms.2006.04.008.

Dempsey D, Suckale J. Induced earthquake sequences in geothermal settings : data trends and modeling approaches. In: Proc 40th Stanford Geotherm Work. Stanford: Stanford University; 2015.

Elders WA, Nielson D, Schiffman P, Schriener A. Investigating ultra high-enthalpy geothermal systems: a collaborative initiative to promote scientific opportunities. Sci Drill. 2014;18:35-42. https://doi.org/10.5194/sd-18-35-2014.

Fischer T, Guest A. Shear and tensile earthquakes caused by fluid injection. Geophys Res Lett. 2011;38:2-5. https://doi. org/10.1029/2010gl045447.

Gan Q, Elsworth D. Analysis of fluid injection-induced fault reactivation and seismic slip in geothermal reservoirs. Solid Earth. 2014;119:1-26. https://doi.org/10.1002/2013jb010500.

Garagash DI, Germanovich LN. Nucleation and arrest of dynamic slip on a pressurized fault. J Geophys Res B Solid Earth. 2012;117:1-27. https://doi.org/10.1029/2012jb009209.

Gischig VS. Rupture propagation behavior and the largest possible earthquake induced by fluid injection into deep reservoirs. Geophys Res Lett. 2015;42:7420-8. https://doi.org/10.1002/2015gl065072.

Häring MO, Schanz U, Ladner F, Dyer BC. Characterisation of the Basel 1 enhanced geothermal system. Geothermics. 2008;37:469-95. https://doi.org/10.1016/j.geothermics.2008.06.002.

Kinnaert X. Data processing of induced seismicity: estimation of errors and of their impact on geothermal reservoir models. Université de Strasbourg, Ph.D. Diss. 2016; p. 1-194.

Király E, Zechar JD, Gischig V, Karvounis D, Heiniger L and Wiemer S (2015) Modeling and forecasting induced seismicity in deep geothermal energy projects. In: Proc world geotherm congr. p. 19-25.

Kohl T, Mégel T. Predictive modeling of reservoir response to hydraulic stimulations at the European EGS site Soultz-sousForêts. Int J Rock Mech Min Sci. 2007;44:1118-31. https://doi.org/10.1016/j.jirmms.2007.07.022.

Majer EL, Baria R, Stark M, Oatesd S, Bommere J, Smithf B, Asanuma H. Induced seismicity associated with Enhanced Geothermal Systems. Geothermics. 2007;36:185-222. https://doi.org/10.1016/j.geothermics.2007.03.003.

Marone C, Scholz CH. The depth of seismic faulting and the upper transition from stable to unstable slip regimes. Geophys Res Lett. 1988;15:621-4. https://doi.org/10.1029/gl015i006p00621.

McClure MW. Modeling and characterization of hydraulic stimulation and induced seismicity in geothermal and shale gas reservoirs. Stanford Ph.D .Diss. 2012; p. 1-369.

McClure MW. The potential effect of network complexity on recovery of injected fluid following hydraulic fracturing. In: SPE Unconv Resour Conf. 2014; https://doi.org/10.2118/168991-ms.

McClure MW, Horne RN. Investigation of injection-induced seismicity using a coupled fluid flow and rate/state friction model. Geophysics. 2011;76:181. https://doi.org/10.1190/geo2011-0064.1.

McClure MW, Horne RN. Characterizing hydraulic fracturing with a tendency for shear stimulation test. Soc Pet Eng. 2013;166332:1-17. https://doi.org/10.2118/166332-ms.

McClure MW, Horne RN. An investigation of stimulation mechanisms in Enhanced Geothermal Systems. Int J Rock Mech Min Sci. 2014;72:242-60. https://doi.org/10.1016/j.ijrmms.2014.07.011.

Meyer G, Baujard C, Hehn R, Genter A, McClure MW. Analysis and numerical modelling of pressure drops observed during hydraulic stimulation of GRT-1 geothermal well (Rittershoffen, France). vol 1. In: Proc 42nd Work Geotherm Reserv Eng. 2017; p. 14. 
Moeck IS. Catalog of geothermal play types based on geologic controls. Renew Sustain Energy Rev. 2014;37:867-82. https://doi.org/10.1016/j.rser.2014.05.032.

Norbeck JH, McClure MW, Horne RN. Field observations at the Fenton Hill enhanced geothermal system test site support mixed-mechanism stimulation. Geothermics. 2018;74:135-49. https://doi.org/10.1016/j.geothermics.2018.03.003.

Piris G, Griera A, Gomez-rivas E, et al. Induced Seismicity in pressurised single fractures: a numerical approach. Geogaceta. 2017;61:95-8.

Prabhakaran R, De Pater H, Shaoul J. Pore pressure effects on fracture net pressure and hydraulic fracture containment: insights from an empirical and simulation approach. J Pet Sci Eng. 2017;157:724-36. https://doi.org/10.1016/j.petro I.2017.07.009.

Rubin AM, Ampuero JP. Earthquake nucleation on (aging) rate and state faults. J Geophys Res Solid Earth. 2005;110:1-24. https://doi.org/10.1029/2005jb003686.

Rutledge JT, Phillips WS, Mayerhofer MJ. Faulting induced by forced fluid injection and fluid flow forced by faulting: an interpretation of hydraulic-fracture microseismicity, Carthage Cotton Valley gas field, Texas. Bull Seismol Soc Am. 2004;94:1817-30. https://doi.org/10.1785/012003257.

Schill E, Genter A, Cuenot N, Kohl T. Hydraulic performance history at the Soultz EGS reservoirs from stimulation and long-term circulation tests. Geothermics. 2017;70:110-24. https://doi.org/10.1016/j.geothermics.2017.06.003.

Scholz C. The mechanics of earthquakes and faulting, 2nd editio. New York: Cambridge University Press; 2002.

Segall P. Earthquake and volcano deformation. New Jersey: Princeton University Press; 2010.

Shou KJ, Crouch SL. A higher order displacement discontinuity method for analysis of crack problems. Int J Rock Mech Min Sci Geomech. 1995;32(1):49-55. https://doi.org/10.1016/0148-9062(94)00016-v.

Tester JW, Anderson BJ, Batchelor AS, et al. The future of geothermal energy - impact of enhanced geothermal systems (EGS) on the United States in the 21st Century. MIT - Massachusetts Inst Technol. 2006; p. 358.

Willis-Richards J, Watanabe K, Takahashi H. Progress toward a stochastic rock mechanics model of engineered geothermal systems. J Geophys Res. 1996;101:17481-96.

Zeeb C, Konietzky H. Simulating the hydraulic stimulation of multiple fractures in an anisotropic stress field applying the discrete element method. Energy Procedia. 2015;76:264-72. https://doi.org/10.1016/j.egypro.2015.07.859.

Zimmermann G, Reinicke A. Hydraulic stimulation of a deep sandstone reservoir to develop an Enhanced Geothermal System: laboratory and field experiments. Geothermics. 2010;39:70-7. https://doi.org/10.1016/j.geothermic s.2009.12.003.

\section{Submit your manuscript to a SpringerOpen ${ }^{\circ}$ journal and benefit from:}

- Convenient online submission

- Rigorous peer review

- Open access: articles freely available online

- High visibility within the field

- Retaining the copyright to your article

Submit your next manuscript at $\boldsymbol{\Delta}$ springeropen.com 